\title{
On the correspondence between
} surface UV observations and TOMS determinations of surface UV: a potential method for quality evaluating world surface UV observations

\author{
John DeLuisi $\left({ }^{1}\right)$, David Theisen $\left({ }^{2}\right)$, John Augustine $\left({ }^{1}\right)$, Patrick Disterhoft $\left({ }^{3}\right)$, Kathleen Lantz $\left({ }^{3}\right)$, \\ Elizabeth Weatherhead $\left({ }^{3}\right)$, Gary Hodges $\left({ }^{3}\right)$, Christopher Cornwall $\left({ }^{3}\right)$, Irina Petropavlovskikh $\left({ }^{3}\right)$, \\ Amy Stevermer $\left(^{3}\right)$, Dennis Wellman $\left({ }^{1}\right)$ and Jennifer Barnett $\left({ }^{4}\right)$ \\ ( $\left.{ }^{1}\right)$ NOAA, Boulder, Colorado, U.S.A. \\ $\left.{ }^{2}\right)$ Aerojet Corporation, Longmont, Colorado, U.S.A. \\ $\left(^{3}\right)$ CIRES, University of Colorado, Boulder, Colorado, U.S.A. \\ $\left({ }^{4}\right)$ University of Utah, Salt Lake City, Utah, U.S.A.
}

\begin{abstract}
A comparison of erythemally weighted surface UV irradiance observations with similar NASA TOMS surface UV determinations is described. Comparisons are made for two observation periods: the Robertson-Berger (R-B) meter period from 1974 to the late 1980s and the current period from 1996 to the present when more sophisticated UVB-1 instruments were used. The more primitive R-B meter observations that comprised the first U.S. UV network are seen to drift downward with respect to those of the TOMS. While the UVB-1 observations did not appear to drift, a substantial bias is noted to exist between the TOMS and the UVB-1 stations collecting observations; the TOMS estimations tend to be higher. A portion of the bias may be attributed to errors in calibration, total ozone, and cosine response of the surface instrumentation. Unaccounted aerosol effects, although not considered to be large in the TOMS estimations, present another source of error. Comparisons are first done for all sky conditions and then for clear sky conditions. The biases typically agree for all sky conditions within the uncertainties of the surface instruments' calibrations, liberally defined as $\pm 5 \%$, implying that the TOMS cloud correction scheme performs reasonably well. Snow cover severely impacts the TOMS observations, giving considerably higher estimations. The biases for clear sky conditions ranged from 15\% to $19 \%$ with no obvious drifts between the satellite and surface observations. The variation in the biases among stations is within the calibration uncertainties of the instruments, but the absolute bias is unexpectedly large. The standard deviations of the clear sky comparisons among all stations are steady at $4.8 \% \pm 0.7 \%$. A plot of the TOMS/UVB-1 ratio versus TOMS cloud reflectivity observations is noisy, but qualitatively suggestive of a possible slight increase ( $\sim 5 \%$ or greater) over the range of clear to overcast skies. The results from these comparisons is believed to be relevant to a WMO goal of uniformly assuring the quality of UV observations made by networks in many countries. The results for clear sky comparisons suggest that a satellite observing system such as TOMS, which provides global coverage daily, might partially serve as a first-order check to quality assure UV observations being made by networks worldwide. Future research should concentrate on determining the causes of the large differences seen between the UVB-1 and TOMS and the range of uncertainties, using a larger array of stations.
\end{abstract}

Key words $U V$-ultraviolet-erythermal-surfacesatellite - TOMS

Mailing address: Dr. John DeLuisi, NOAA/ARL, 325 Broadway, Boulder, CO80303, U.S.A.; e-mail: john.j.deluisi@noaa.gov

\section{Introduction}

During the past three decades the anticipated threat of a serious stratospheric ozone reduction due to human industrial activities has stimulated public and scientific concern over 
environmental impacts. This motivated a strong movement among nations to seek a definitive answer on the environmental and human health consequences of increased UV-B radiation (hereafter UV-B) exposure. In response to this concern, the first UV-B network was initiated in 1974 and made use of the Robertson-Berger (R-B) meter (Berger, 1976). Later, in the 1990s, several U.S. agencies established UV monitoring programs to acquire scientific data that would further shed light on UV-B exposure rates in various regions of the continental U.S. (Kaye et al., 1999). Other countries, including Canada, Japan, Argentina, New Zealand, Australia, and several European countries, have also established monitoring programs. The World Meteorological Organization (WMO) has been actively coordinating the UVB observing activities of participating countries including the World Climate Research Program's international Global Atmospheric Watch (GAW) environmental monitoring network.

A UV monitoring network requires measurements in terms of absolute radiation quantities, i.e. radiance or irradiance. Moreover, the wavelength region of the surface UV spectrum of interest is roughly between 295 and $400 \mathrm{~nm}$ commonly referred to as the UV-B, $280 \mathrm{~nm}<$ $<\lambda<320 \mathrm{~nm}$, and UV-A, $320 \mathrm{~nm}<\lambda<400 \mathrm{~nm}$, regions of the solar electromagnetic spectrum. UV levels in this region change by about five orders of magnitude from the shortest to the longest wavelength because of the dramatic increase in ozone absorption with decreasing wavelength in the Huggins band. This behavior places severely stringent requirements on the design and construction of rugged observing instrumentation, including accurate wavelength registration, linearity, detector sensitivity, and long-term stability; correspondingly, quality instrumentation costs can soar. The state-of-theart in atmospheric UV measurement technology is still evolving although many advances have been made over the past several years. Newer instruments include the Brewer double dispersion spectrophotometer, the Yankee Environmental Systems' UV Multi-Filter Rotating Shadowband Radiometer (UVMFRSR) (Bigelow et al., 1998), and the U-111 spectroradiometer. The latter two are operated by the Department of Agriculture
(http://nrel.colostate.edu/UV-B). Broadband sensing instrumentation includes Yankee Environmental Systems' UVB-1, Solar Light's Biometer (SL), Kipp and Zonen's UV-S-E-X, and EKO's MS-212D. Calibrations of these instruments are critical and laborious because their spectral response functions and hemispheric irradiance collectors must be well characterized. Moreover, contending with the unpredictable behavior of standard lamps presents a continuous struggle to maintain reliable laboratory irradiance standards. For instance, users of such lamps must contend with their temporal stability, weak UV irradiance output, requirement for highly accurate measurement of electrical power consumption, and susceptibility to changes from slight physical shock or just aging on a shelf.

In view of the care that must be given to general instrumentation maintenance, including calibrations, field performance surveillance, data quality control, as well as hazards such as lightning strikes, winds, snow, hail, and curious animals gnawing on electrical cables, it is easily understandable that data quality can be unintentionally compromised. For this reason, it is imperative that whenever possible the quality of long-term observations be evaluated by comparison with other observations containing information that can be related in some manner to a UV observation. In the case of the National Oceanographic and Atmospheric Administration's (NOAA) Air Resources Laboratory (ARL) Surface Radiation monitoring network (SURFRAD) observations, other types of solar irradiance observations are made. These additional observations are used to check the daily features of the UV observations. For additional information on SURFRAD see Augustine et al. (2000) and the NOAA Surface Radiation Research Branch home page: www.srrb. noaa.gov.

Daily UV observations of NASA's Total Ozone Mapping Satellite (TOMS) described by Herman et al. (1996) offer a practical, daily model-dependent observation that can be compared with SURFRAD's UV-B network observations. Moreover, because the TOMS is a global observing system, comparisons between it and other networks would be useful for quality assurance checks and to some extent as an 
independent check to determine how well other observing networks agree among each other. The main intent of the present investigation is to assess the stability of the previous R-B meter network observations, and the current UV-B observations collected by the SURFRAD network, using TOMS observations to compare with both.

\section{Observations}

The first surface data set that is used to compare with the TOMS data was produced by the R-B meter network (DeLuisi and Harris, 1983; Scotto et al., 1988) and the second data set, collected later by the NOAA Air Resources Laboratory's SURFRAD network, using the UVB-1. Although the fundamental design principles of the two types of instruments are similar, later modifications produced a substantial improvement in field performance characteristics.

The first UVB network that was deployed over the U.S. was operated jointly by NOAA and Temple University (Berger, 1976). The network used the R-B meter that was manufactured by Temple University in accordance with Robertson's (1972) design. The meter was not thermally stabilized and, therefore, suffered error from temperature fluctuations (Blumthaler and Ambach, 1986). Network data were archived at the NOAA Air Resources Laboratory and the National Institute of Health. Calibration and maintenance records have not been published. It is noted here that the Robertson-Berger meter network is a separate entity that operated a first-generation instrument and has no connection with the SURFRAD network and other contemporary networks. The R-B meter network began scaling down in size after 1986 and no longer exists. Current networks operate much-improved, updated instruments that are thermally stable and made rugged for long term field operation.

The purpose for including the R-B meter data in this comparison is historical and meant to provide a perspective for a possible physical explanation for the negative trend in UV observations reported by Scotto et al. (1988).
The trend occurred during the years 1974 to 1985 when a slightly positive trend could be expected from an ozone decrease of $\sim 5 \% /$ decade reported by Bojkov et al. (1990).

The SURFRAD's UV observations are obtained with the Yankee Environmental Systems (YES) broadband UVB-1 instrument (www.yesinc.com). Routine annual instrument checks and calibrations are performed by the Central UV Calibration Facility (CUCF) located at the NOAA office of Oceanic and Atmospheric Research (OAR) facility in Boulder, Colorado (Lantz et al., 1999). The calibration records of the SURFRAD UV-B instruments indicate that calibration changes are mostly contained within a few percent or less per year, which is within the uncertainty limits of the routine re-calibration process. Such stability is highly desirable for maintaining a credible record of long term observations needed for critical scientific applications such as environmental impact assessments, trend analysis, and satellite data verification.

Information on the TOMS satellite and UV observations can be found in Herman et al. (1996). Basically, the TOMS observes total ozone and tropospheric reflectance each day over the entire globe. The total ozone observations are used to model the incident surface UVB irradiance, and the reflectance is used to estimate the cloud transmittance of UV to the surface, with the assumption that cloud absorption might be negligible, i.e. that conservative scattering applies (Schafer et al., 1996; McKenzie et al., 1998). It is yet to be shown that some absorption is possible, especially with polluted clouds. Because of their highly variable optical properties, the effects of tropospheric aerosols remains an open question, but have been investigated for example by Krotkov et al. (1998) using TOMS observations. An investigation by Wenny et al. (1998) found that tropospheric aerosol absorption in the UV can be quite variable and sometimes strong.

The surface UV irradiance measurements and the computed TOMS estimates of UV-B are slightly different: the Spectral Response Functions (SRF) of the various broadband instruments do not strictly emulate the average human skin erythematogenic action spectrum 
while the TOMS UV retrievals are calculated for the Diffey (1991) average human skin erythematogenic action spectrum. Therefore, correction schemes are often used to adjust the measurements to more accurately represent the human skin response. Nevertheless, because of the unique design of the field instruments, their performance is seen to be remarkably stable with time and, furthermore, display exceptionally good agreement and stability among the array of network instruments' spectral response functions (DeLuisi et al., 1992). This trait is highly desirable for continuous long term monitoring observations.

\section{Procedure}

Five R-B meter monitoring stations were chosen for comparison with TOMS. The comparison begins in 1980 and ends in 1990 . A five station subset, Albuquerque $(35.1 \mathrm{~N}$, 106.4W), El Paso (31.5N, 106.3W), Minneapolis (44.6N, 93.2W), Philadelphia (39.6N, 75.1W), and Tallahassee $(32.3 \mathrm{~N}, 85.5 \mathrm{~W})$, is considered representative of the eight station set used by Scotto et al. (1988), because the annually averaged data series closely follows that of the eight stations. These stations were also chosen because of their proximity to Dobson ozone observing stations providing total ozone information for modeling UVB irradiance at the R-B meter stations. Unfortunately, the overlapping periods of the TOMS and surface UVB observations are incomplete, but useful information is derived to provide insight into the Scotto et al. (1988) analysis showing a negative trend.

The R-B meter calibration is in terms of relative units of exposure which are converted into sunburn units. The procedure used to make the RB-meter data equivalent (in units of relative counts per half hour) is to work with normalized observations, viz., departures from the mean of the observation record. This removes any bias, but is useful for determining drifts and climatic variation correspondence between the two. In addition, the procedure removes any seasonal differences such as found by Kalliskota et al. (2000). The more updated YES and SL instru- mentation data are in terms of absolute irradiance units, $\mathrm{W} / \mathrm{m}^{2}$, and furthermore, can be reasonably adjusted for the SRF difference by accounting for total ozone and solar zenith angle disparities (Lantz et al., 1999) that have been determined during calibration. To reduce solar zenith angle dependence, only data obtained near solar noon are used; the timing happens to be close to the time of the TOMS overflight.

The TOMS is normally in noon orbit, meaning that the station overpass time will be close to noon and large day-to-day variations in solar zenith angle that affect the performance of instruments such as the R-B meter and the UVB-1 can be avoided. Corrections for solar zenith angle and total ozone variations are available. Tests were performed to quantify errors relating to these factors. The obtained results implied errors on the order of $1 \%$ and are not serious.

It was decided to calculate a one-hour average of SURFRAD surface UV-B irradiance around local noontime as a means of averaging cloud effects in the surface instrument's hemispheric field of view. An additional benefit of the noontime comparison is that the solar zenith angle is not changing rapidly. Therefore, the hourly average will only be slightly lower than the exact peak value at solar passage over the local meridian. Calculations using 3-min average clear-sky values of observed irradiance indicate that the error between the precise noontime value and the hourly-averaged value around noontime is $\sim 1 \%$ or less. The report by Long et al. (1996) also supports this argument.

The surface footprint of the TOMS is approximately $50-100 \mathrm{~km}$ in diameter; comparisons during the presence of clouds are, therefore, expected to be noisy compared to clear sky conditions. On the other hand, an hourly average of clear sky UV-B irradiance values can be expected to usually represent a reasonable portion of clear sky conditions over a large region. The method of Long and Ackerman (2000) was applied to SURFRAD observations to obtain the times of clear sky conditions. Clear skies over a site can also be determined by the TOMS reflectivity channel signal, i.e. reflectivity $<5 \%$. Both kinds of information were used in our analysis with no significant difference noted in the results. 


\section{Results}

\subsection{Comparison of TOMS with the R-B meter network}

Figures 1 to 3 are comparisons of TOMS UV-B with the RB-meter UVB observations. The three surface stations are El Paso, Albuquerque, and Philadelphia, respectively. The plots consist of deseasonalized quarterly averages of the TOMS and UVB data sets, normalized to the mean value of their respective entire record. The deseasonalizing procedure removes any possible seasonal difference between the two data sets such as found by Kalliskota et al. (2000). Note that the plots shown in figs. 1 to 3 are normalized data, as mentioned previously, because R-B meter units are in terms of counts per half-hour while the TOMS UV-B data are in terms of $\mathrm{W} / \mathrm{m}^{2}$. Wintertime TOMS data will most likely be in error over snow-covered surfaces. This effect occurs because the satellite tropospheric reflection channel senses the snow as cloud cover and falsely estimates the calculated clear- sky UV cloud transmission correction factor when the actual cloud cover can be minimal. In these figures a downward drift of the R-B meter observations at El Paso and Albuquerque is seen. The plotted Philadelphia data appear to track quite well, within $\sim 5 \%$, and show no apparent drift with respect to the TOMS observations. The observations from this station seem to fluctuate more than the other two stations shown. It is believed the reason is that greater variation in regional cloud and aerosol climatology exists in the eastern part of the U.S. as compared to the more westerly stations where cloudless skies are more prevalent. The Philadelphia R-B meter was used as the Temple University's primary standard to calibrate instruments rotated from the field and to calibrate secondary traveling standard instruments for side-by-side comparison in the field. Apparently, the transfer of calibrations to the field instruments by traveling standards was a problem that might not have been adequately resolved. One may notice when reviewing the Philadelphia data plot of Scotto et al. (1988) that the average annual values were high before

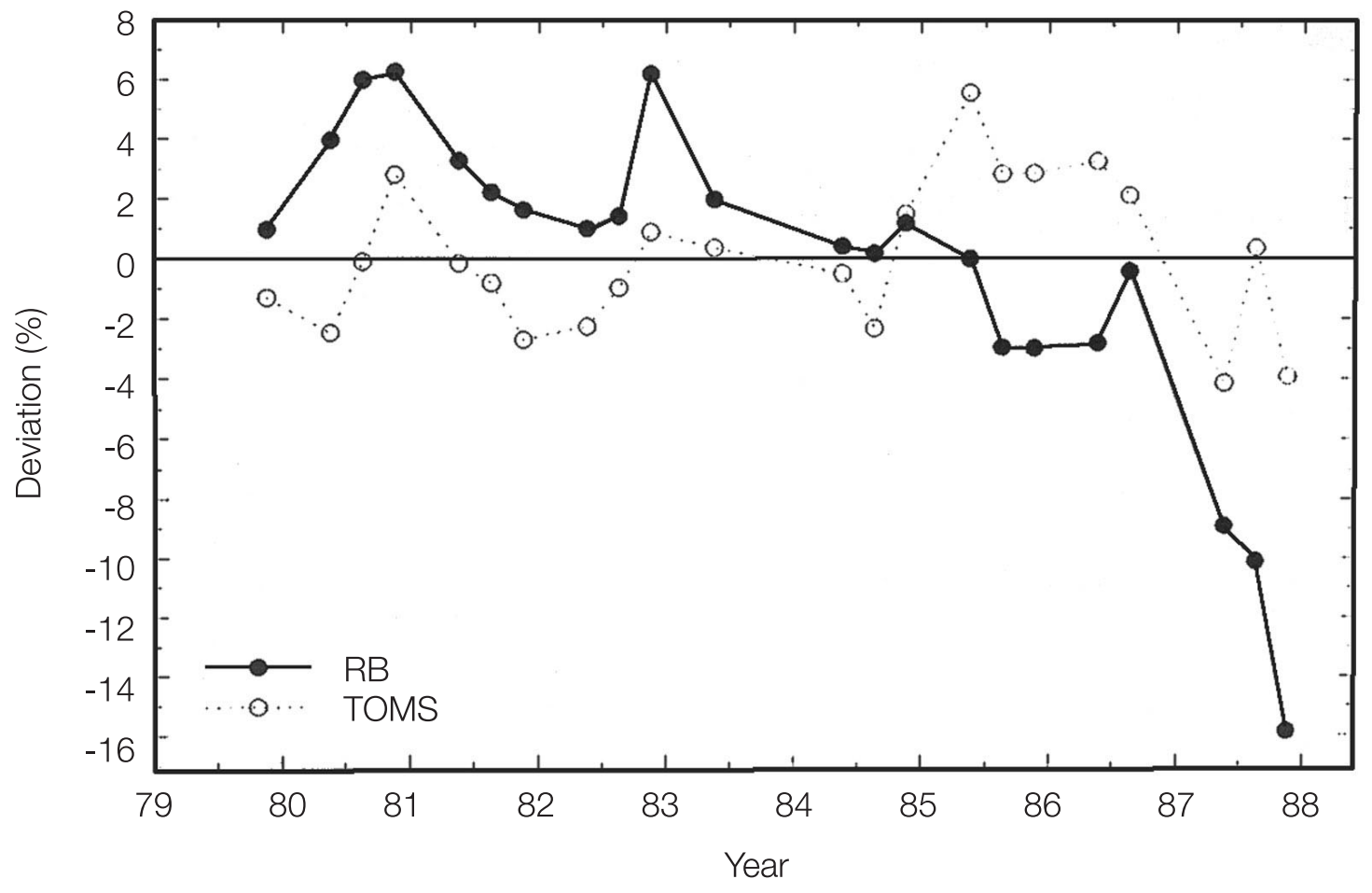

Fig. 1. Time series comparison plots of quarterly averaged deseasonalized TOMS UV-B and R-B meter UV-B deviations at El Paso, TX. 


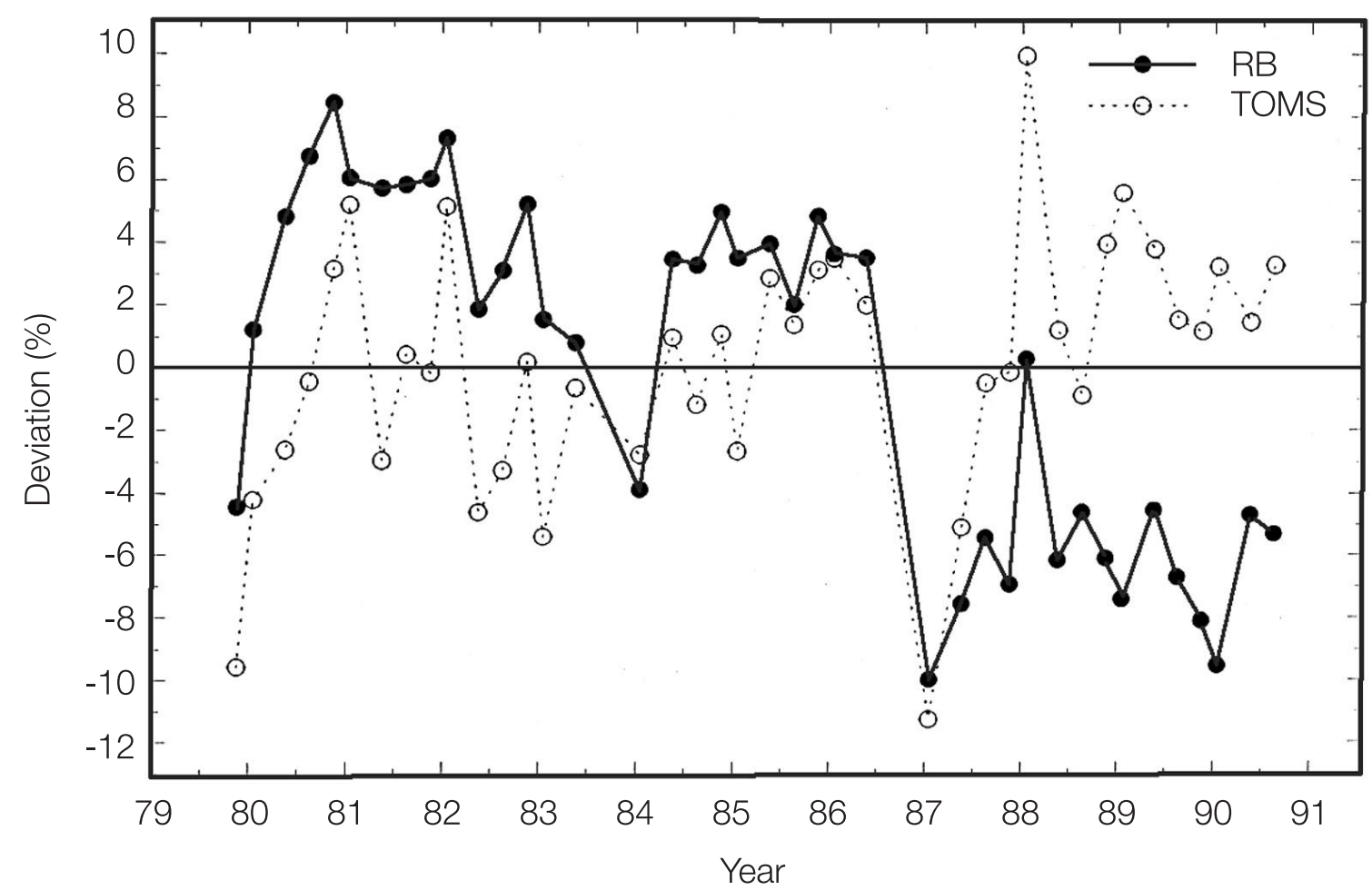

Fig. 2. Same as fig. 1, but for Albuquerque, NM.

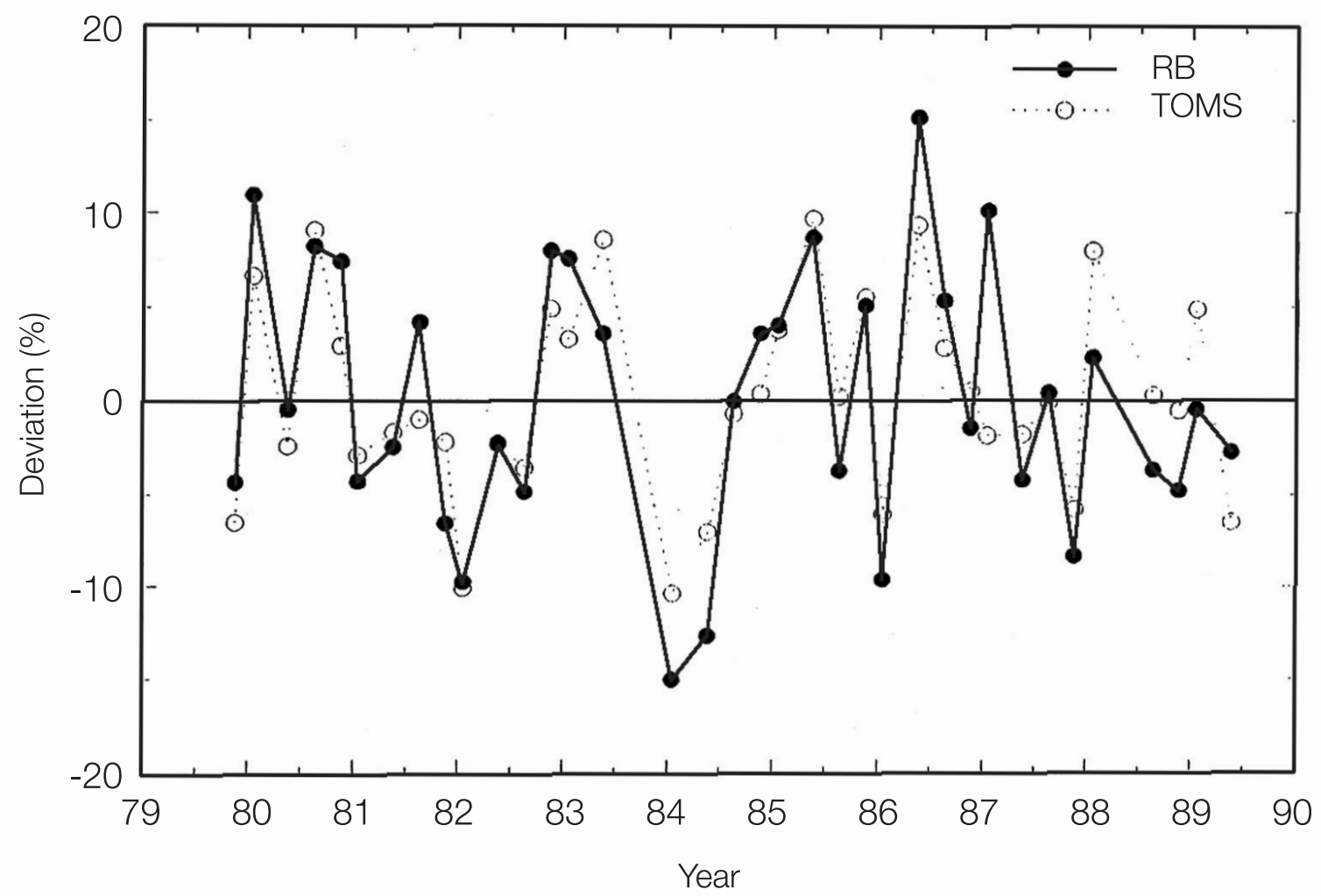

Fig. 3. Same as fig. 1, but for Philadelphia, PA. 
1980 compared to the data after this time. The Minneapolis and Tallahassee station comparisons (not shown) were noisier than those shown in figs. 1 to 3.

Next, in fig. 4 we compare the five station average, starting in 1974, with the averages of TOMS observations over the same stations. The R-B meter observations in general are high before 1979-1980 and indicate a downward tendency. There is no indication of a downward trend in the TOMS data. The plotted 1982 and 1983 points of the TOMS, which were lower than the others, reflect lower values appearing over the eastern stations at that time. If these points were neglected, one might argue the existence of a slight upward trend for this time period, more consistent with the Bojkov et al. (1990) findings.

Figure 5 compares estimated R-B meter calibration differences between Temple University's actual R-B meter calibrations for the stations under study and the present investigation estimated clear sky calibrations using total ozone observations from Dobson and TOMS instruments and the raw uncalibrated signals from the R-B meters. The ordinate zero line is the reference to the sky calibration. Each station symbol is located at the midpoint of a period during which an assigned calibration was in effect. The procedure for calculating surface irradiance that was used to calibrate an R-B instrument if fundamentally similar in principle to that of the TOMS, which also theoretically computes clear sky UVB surface irradiance using total ozone observations. Previous to 1979-1980, most of the differences are positive and contained in the range of 0 to $4 \%$. After 1980 , most of the differences are below the zero line. From an average of values before and after the shift, we estimate a total shift of about $4 \%$. The same figure shows a calibration difference trend of $-6 \%$ /decade (apparently the $4 \%$ shift produces a greater trend), which is in the range of the trend reported by Scotto et al. (1988). If the total ozone trend reported by Bojkov et al. (1990) actually occurred over the five stations during the period of the present analysis, then the Temple University calibration drift might be much greater, of magnitude $-8 \%$ to $-10 \%$ or greater. On the other hand, the present investigation also examined the total ozone over the five stations and no significant trend was indicated. This result leads us to conclude that the $4 \%$ shift is mainly responsible for the trend reported by Scotto et al. (1988), and that there was very likely no significant trend in the UV, on the average, at least for the five stations examined in the present investigation.

Around 1979-1980, the Temple University R-B meter laboratory calibration standard was changed from a weak power output quartz halogen standard lamp to a more powerful xenon lamp with the intent to improve the radiant power output of their calibration procedure (private communication, Dan Berger circa 1989). This is a very important point because the spectral emissions of these lamps are quite different. The transfer of a broadband UV calibration to an instrument, having a complex broadband spectral response function calibration such as the $\mathrm{R}-\mathrm{B}$ meter, with dissimilar irradiance standards is a complicated process.

This section concludes with the suggestion that the cause of the negative trend in UV-B reported by Scotto et al. (1988) is due to procedural changes in calibration accompanied by fluctuating, moderate uncertainties $\sim 5 \%$ encountered in transferring calibrations to the field instruments. The results also confirm the conclusions of the investigation by Weatherhead et al. (1997) who performed a statistical analysis on the R-B meter observation record. It is highly unlikely that increased aerosol loading over all stations would be responsible for the negative trend. There is little evidence, if any, that aerosols increased sufficiently to impact on the UV observations made at different locations. Furthermore, if aerosols were responsible, then why was Philadelphia not affected? Philadelphia is located close to the heart of the eastern seaboard high turbidity region (Flowers et al., 1969). The work of Wenny et al. (1998) indicated that aerosol absorption can be strong, but their recently obtained aerosol optical depth data also suggested no aerosol trend in the Central North Carolina region since the time of the Flowers et al. (1969) investigation. Unfortunately, there are no systematic observations for determining aerosol optical depth trends that are available to unambiguously qualify any statements con- 


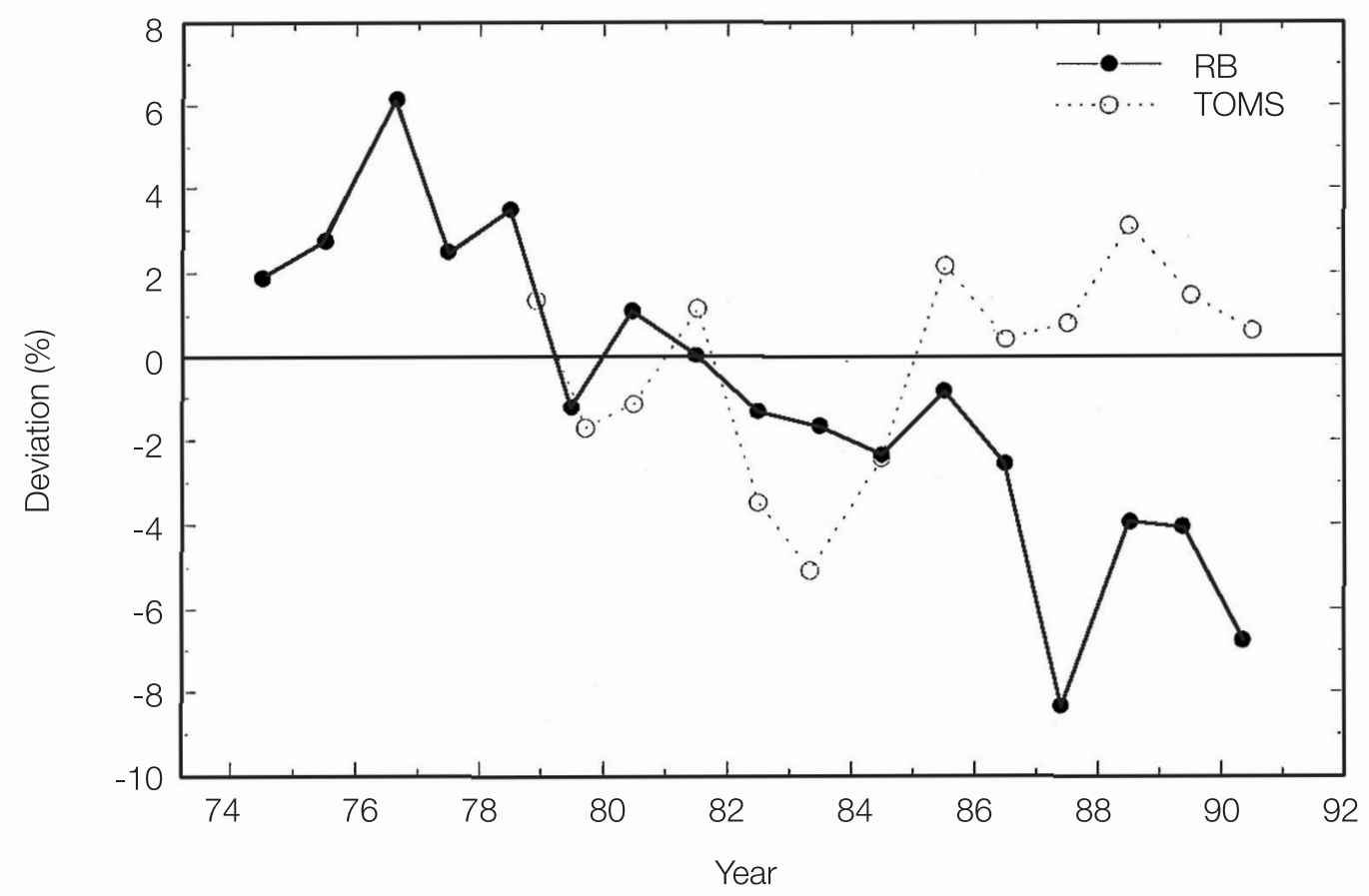

Fig. 4. Time series plots of deseasonalized average annual observed UV-B deviations from the mean at five stations (see text) in the R-B meter network that were included in the Scotto et al. (1988) trend analysis and deseasonalized average annual TOMS observed UV-B deviations over the same stations.

\section{Scotto - Estimated \\ Five Stations}

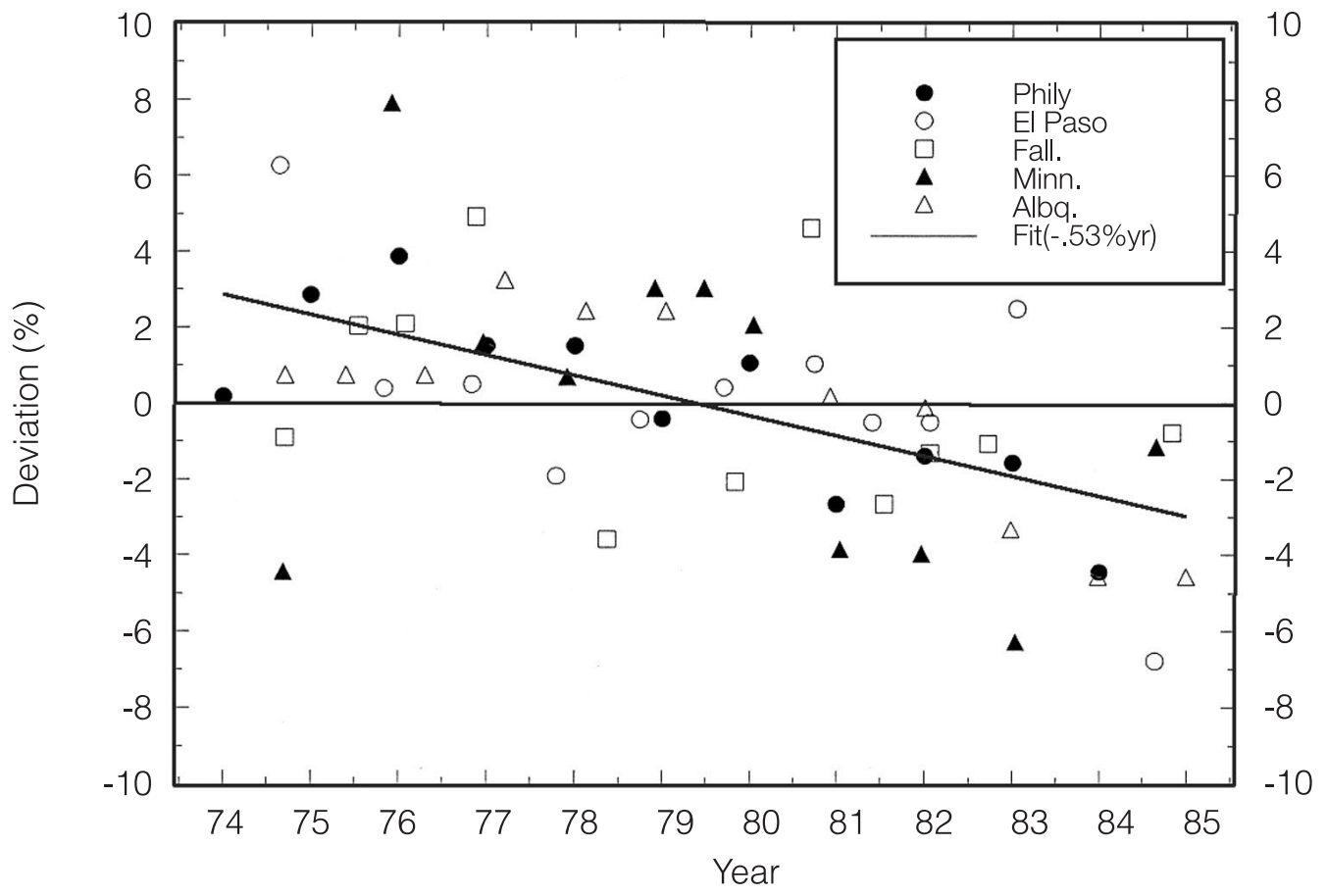

Fig. 5. Time series plots of Temple University calibrations minus reconstructed calibration deviations from the mean showing a period of high values up to 1980 followed by low values thereafter, indicating roughly a shift of 4\%. Compare this figure with fig. 4. 
cerning aerosol affected UV trends at the monitoring stations' locations.

\subsection{Comparison of TOMS UV with SRRB broad- band $U V$-B irradiance observations}

Figure 6 shows a plot comparing TOMS overpass UV-B observations with Goodwin Creek UV-B observations for all sky conditions (clear and cloudy) from 1996 to 1998. The plotted diamonds represent the percent difference as (TOMS-UV)/UV. Ozone corrections were applied to the surface UV-B measurements. The bias between the two observations is $20.5 \%$ with TOMS being higher. The standard deviation is $21.5 \%$ which is not unexpected because of the satellite's large foot print and the nonhomogeneity of scattered clouds.

Figure 7 is a plot of Goodwin Creek comparisons for the same period as in fig. 6, but for cloud free skies. In this analysis the bias is $18.1 \%$, and the standard deviation is now reduced to $4.1 \%$. The results for the stations at Bismarck (46.5N, 100.5W), Bondville (40.1N, 88.4W), Boulder $(40.1 \mathrm{~N}, 105.2 \mathrm{~W})$. Fort Peck (48.3N, 105.1W) and Goodwin Creek (34.3N, 89.98W) are tabulated in table I. The Bismarck station is a NOAA solar radiation monitoring station belonging to a different network (Hicks et al., 1996) that uses a Solar Light UV Biometer.

In the all sky cases, with the exception of Fort Peck and Boulder, TOMS errors caused by snow cover were removed. The effects of snow cover show up dramatically at Fort Peck in fig. 8 and to a lesser extent at Boulder (not shown). Snow cover at Fort Peck in the fall and winter of 1997-1998 produced a nearly $\sim 100 \%$ negative deviation from the average clear sky values. Note the distinct boundaries of the snow effect for the winter of 1996-1997, indicating the continuous presence of snow cover in the region, marked by a rapid increase in the fall and a rapid decrease in the spring. Also, note the remarkable difference in snow cover for the winters of 1996-1997 and 1997-1998. Obviously, any analysis that involves

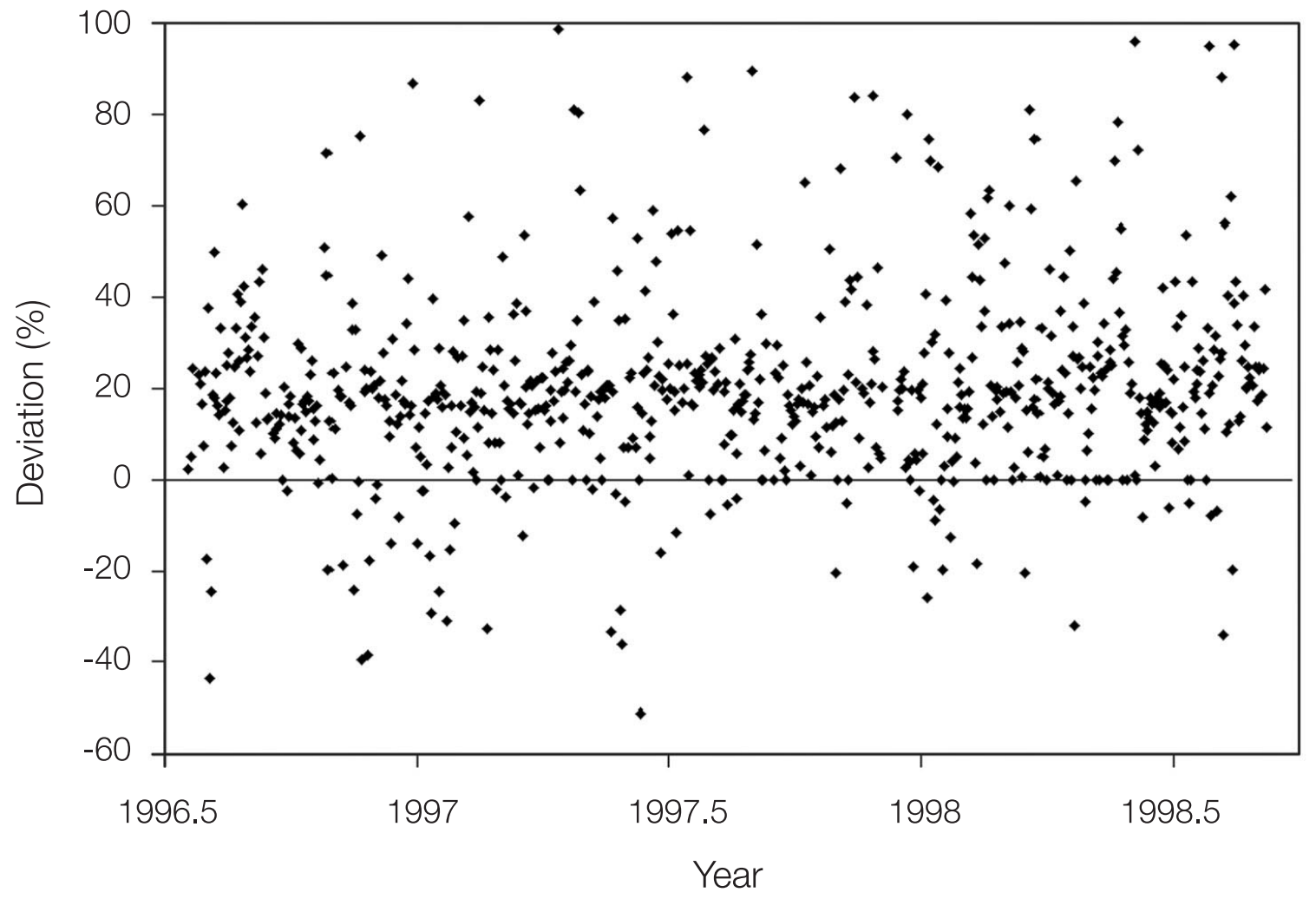

Fig. 6. Percent deviation of the difference between satellite and surface UV-B observations, TOMS minus UVB-1, for all sky conditions. The site is Goodwin Creek, MS. 


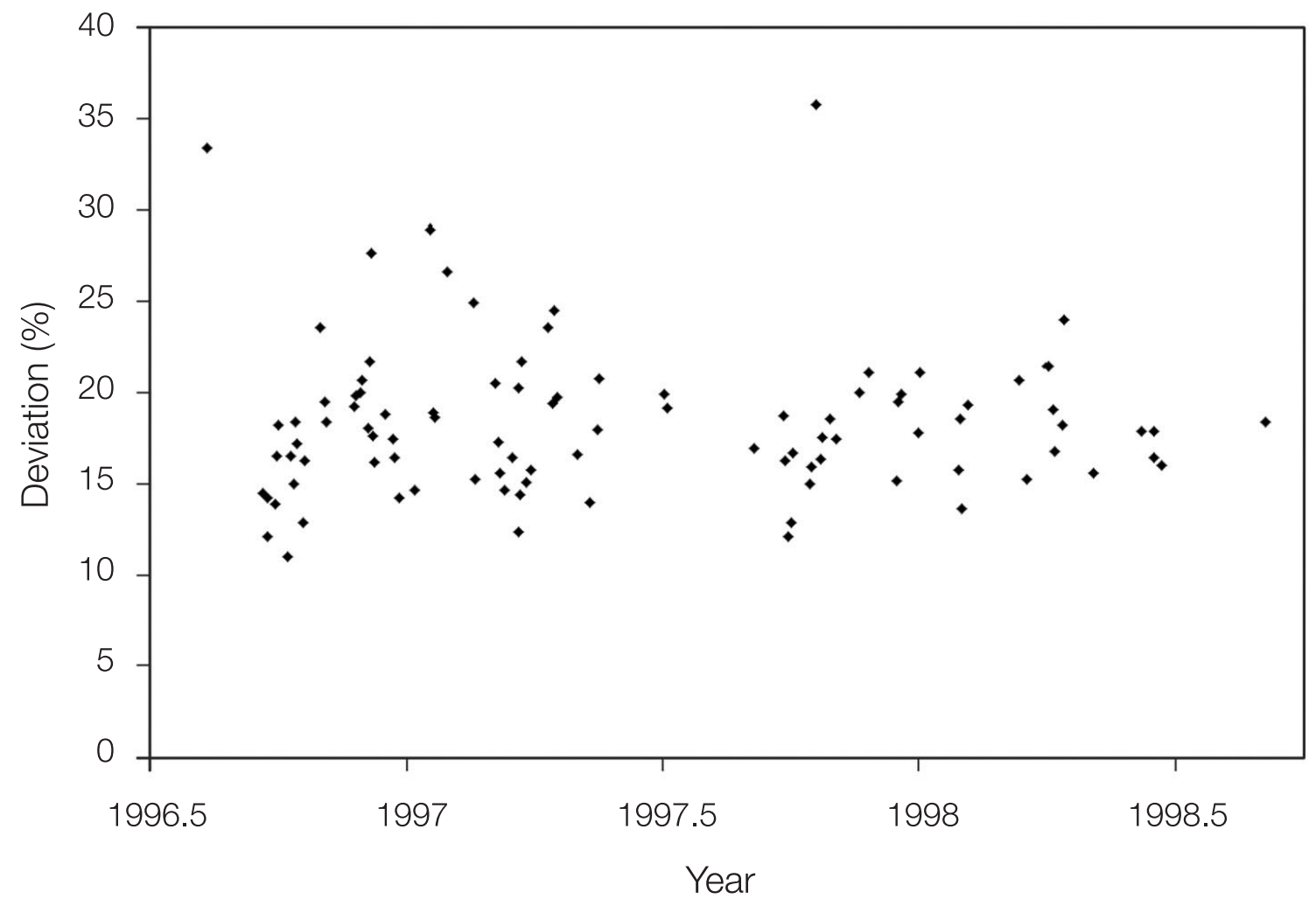

Fig. 7. Same as fig. 6, but for cloud free sky conditions.

Table I. Comparisons of TOMS UV-B with SURFRAD UVB-1 observations of surface UV-B for five stations and for all sky and clear sky conditions. Bismarck, North Dakota results represent a special case. The snow cover error for the all sky case was not removed from the Fort Peck and Boulder data.

\begin{tabular}{lccccc}
\hline \hline \multirow{2}{*}{ Location } & \multicolumn{3}{c}{ All sky } & & \multicolumn{2}{c}{ Cloud free sky } \\
\cline { 2 - 3 } \cline { 5 - 6 } & \%Bias & \%SD & & \%Bias & \%SD \\
\hline Bondville, IL & 17.0 & 30.2 & & 19.2 & 5.5 \\
Boulder, CO & 10.6 & 27.9 & & 15.6 & 4.3 \\
Fort Peck, MT & 0.44 & 51.1 & & 17.1 & 5.2 \\
Goodwin Creek, MS & 20.5 & 21.5 & & 18.1 & 4.1 \\
Bismarck, ND* & 24.5 & 29.3 & & 17.9 & 4.9 \\
\hline
\end{tabular}

* The UV instrument at Bismarck is a Solar Light UV Biometer.

TOMS observations over snow-covered surfaces will be subjected to large uncertainties. This interesting phenomenon may be a way to depict the presence of significant snow cover over a large region as viewed by a satellite, in contrast to point measurements of surface reflectance at the surface. The presence of clouds can confound the actual snow cover surface area (bare versus snow) interpretation of the points intermediate to the maximum and minimum. However, with the TSI observations, or with the use of SURFRAD cloud cover information, derived by the Long and Ackerman (2000) method, it seems possible that an interpretation of the intermediate points (i.e., 


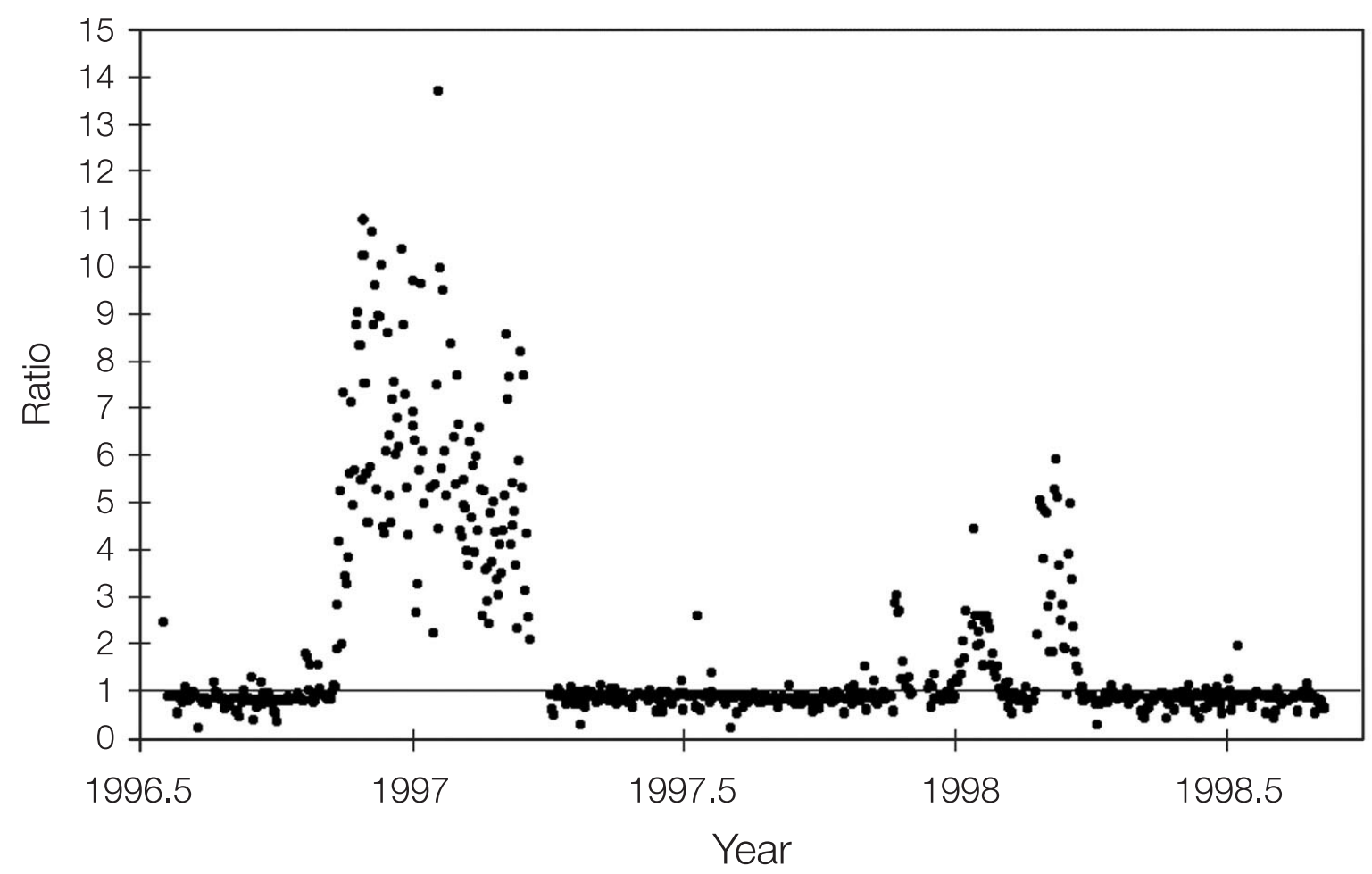

Fig. 8. Deviation of the ratio TOMS/UVB-1 compared to no snow observations (lowest values) at Fort Peck, MT, showing error effects of snow cover on TOMS UV-B retrievals.

partial snow cover, versus complete snow cover) can be quantified.

From this limited sample of comparisons, the range of consistency among the network instruments' observational bias for clear skies is $\sim 4 \%$. This value is in the range of the year-to-year broadband instrumentation relative calibration uncertainty that existed during the earlier stages of the SURFRAD network operations. The consistent $\sim 5 \%$ standard deviation or less is quite surprising and should be further examined to determine whether it is a characteristic feature of clear sky comparisons over a larger sample of stations. Also, it is possible that the method for selecting clear sky data may have some influence. Nevertheless, the present results suggest that clear sky UV-B transmission may not be so erratic to contend with. It would be useful to extend the present investigation to other stations to confirm the present results. Considering the difficulties of UV-B monitoring, a station-tostation range of comparison uncertainty, even $\sim 5 \%$, is forgivable at the present stages of the developing monitoring networks, and especially in light of the difficulties of maintaining long term irradiance observations.

If the small range of differences holds for other stations, then it might be worthwhile for an organization to establish a global UV-B quality assurance program utilizing the TOMS observations to help UV-B monitoring station managers feel secure that their observations are acceptable and to help certify their long-term measurements for placement in national and international archives. Also, it seems feasible that with the use of a satellite, the observations from remote stations that are not directly tied to advanced calibration laboratories could be compared against stations that are tied to the available laboratories, for example, the Boulder CUCF, and Italy's Lampedusa Island station operated by Italian scientists (Di Sarra et al., 2001) where systematic spectroradiometric UV observations, with instruments possessing calibrations tied to the CUCF, are being made. A small island station such as Lampedusa, $2 \times 10 \mathrm{~km}$, is ideal for verifying satellite algorithms because of the uniformity of the surrounding sea surface 
albedo that is also included in the satellite's field of view.

The large bias between the satellite and surface observations is puzzling and can not be ignored. Possible sources contributing to the large disparity are total ozone error, irradiance collector cosine error, aerosol absorption not included in the TOMS retrievals, and surface instrument calibration factor errors. Even so, in light of these possible factors, it is difficult to rationalize that the total error would be as large as that being experienced here. At most, the total contribution should possibly amount to not more than a few to several percent. The TOMS UV-B retrieval algorithm should be further checked because previous comparisons also indicated that TOMS is giving higher values than surface observations (e.g. see Eck et al., 1995).

\subsection{Examination of the TOMS cloud correction scheme}

A simple analysis of the quality of the TOMS cloud correction scheme was performed by plotting the ratio of surface UV observations to TOMS as a function of the TOMS reflectivity channel value. The result is shown in fig. 9. The percent difference value for low reflectivity is close to the value for clear sky conditions ( 15\%-19\%), but as the reflectivity increases the percent difference appears to change. Visually, one could perceive a slight increase in the ratio (an increase of $\sim 10 \%$ ) when approaching the highest reflectivity conditions. The very highest values in the $90 \%-100 \%$ reflectivity range are believed to be unreliable. If the ratio increase is real, then it could indicate that the TOMS cloud correction scheme is slightly under-correcting with increasing cloudiness, i.e. the transmission estimation needs to be lower with increasing cloudiness/reflectivity. Or, alternatively, the cosine error of the surface UV instruments is responsible, as increasing cloud cover increases the magnitude of the diffuse sky radiation contribution to the hemispheric irradiance field (Lantz et al., 1999). On the basis of results from routine cosine error measurements of UVB-1 instruments, as performed by the CUCF, a discrepancy of approximately $-5 \%$ could be

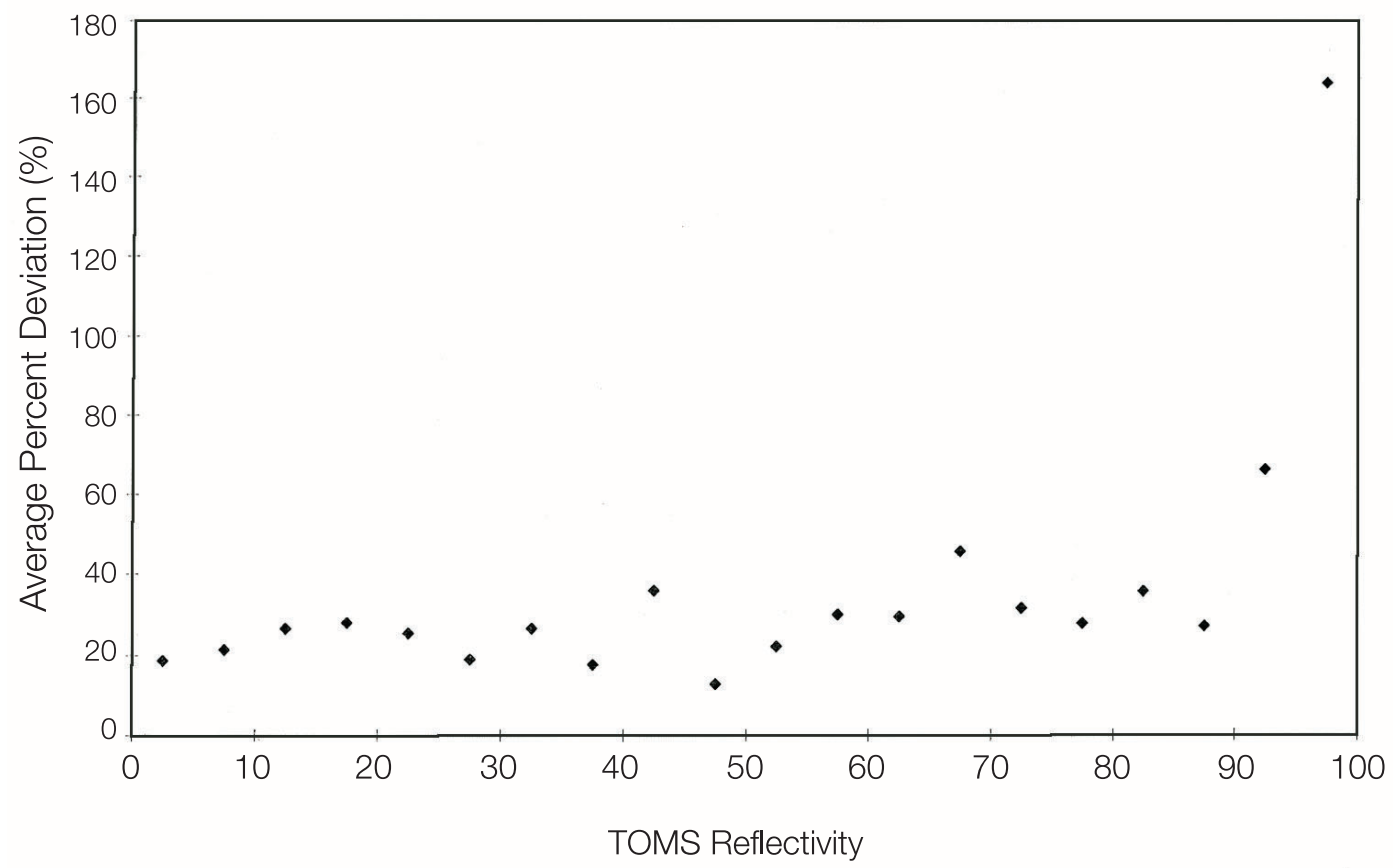

Fig. 9. Percent deviation of the ratio TOMS/UVB-1 observations versus TOMS reflectivity observations, suggesting a possible slightly non-linear effect in the TOMS cloud correction scheme. 
expected for completely overcast skies. TOMS cloud transmission is calculated as a linear process and this assumption might not hold exactly for increasing cloud cover. The scatter in the plotted points makes it difficult to definitively quantify an increasing tendency, with increasing cloud cover, as seen in the plotted points of fig. 9. Accordingly, the result suggests that the cloud correction scheme and the cosine error of the surface instruments are good candidates for closer scientific examination. Cloud fraction data as well as solar and UV irradiance data for six stations are now available in the SURFRAD data archive (Augustine et al., 2003). The data from this network should be suitable for testing the two hypotheses.

\section{Conclusions}

The analysis presented in this report uses NASA TOMS UV-B observations as a tool for qualifying scientific data derived from surface UV-B networks. Results of the present analysis of earlier R-B meter network UVB data that were compared with those of the TOMS imply that the cause of the unexpected negative trend reported by Scotto et al. (1988) is most likely due to erratic calibrations of the R-B meter network instruments and a downward shift in their calibrations occurring around 1979-1980. This shift in calibrations is likely to be the most overwhelming factor responsible for the trend that was reported in the Scotto paper. From 1978 to 1990 the R-B meter data show a downward trend while the TOMS data, starting from 1979 show some variations, but tend towards higher values than the R-B meter from 1986 onward.

Comparisons of TOMS UV-B observations with observations by upgraded UV-B instruments operating in a contemporary network revealed a substantial clear sky bias in the range $15 \%$ 19\%, with TOMS higher. All sky conditions biases are on the same order, but the individual day comparisons are much noisier. The standard deviations of the clear sky comparisons is $4.8 \% \pm 0.7 \%$ for all stations. At least part of the large bias is believed to be due to errors related to ignoring small ozone corrections, solar zenith angle corrections, and a possible systematic error in the calibration procedure. Errors in the TOMS UV-B retrieval algorithm need to be considered as well. In spite of the bias, a positive aspect of the comparison suggests that it might be feasible to use the TOMS as a means to check a variety of UV observations made by monitoring stations world wide since the standard deviations of the comparisons for clear skies is $\sim 5 \%$. A few of the stations having direct connections with a qualified calibration/research laboratory might serve as regional primary stations to serve as a reference for the satellite and those stations that the satellite overflies. However, it needs to be shown that a larger number of stations will behave in a fashion similar to the five stations examined in the present paper. An endeavor such as this could be mandated by a responsible authority such as the WMO.

The TOMS cloud transmission scheme was examined over the range of clear sky to overcast conditions as determined by examination of the TOMS reflectance channel. There appears to be a slight increase in the cloud-corrected TOMS UV-B determinations with increasing cloudiness, but the data are noisy. More work is required to reach a reliable conclusion. It is suggested that the NOAA SURFRAD network observations of UV-B and cloud cover fraction might be suitable for further testing of the TOMS cloud correction scheme.

The Atmospheric Modeling of Radiation Experiment (AMORE) project (see USDA web site) that was conducted at Boulder, Colorado, this past summer will compare theoretical calculations of UV-B with observations made by several UV-B radiometers ranging in technological complexity from high precision double monochromators to single broadband sensors. It is envisioned that this project will help resolve some current issues involving causes for the differences seen between modeled and measured UV-B.

\section{Acknowledgements}

Support for this investigation was provided by the NOAA Office of Global Programs, Project \# GC97-263, and the National Aeronautics and Space Administration project \# S-67815-Z. The 
kind assistance received from Drs. P.K. Bhartia, J. Herman, and R. McPeters of NASA, Goddard is deeply appreciated.

\section{REFERENCES}

Augustine, J.A., J.J. DeLuisi and C.N. Long (2000): SURFRAD - A national surface radiation budget network for atmospheric research, Bull. Amer. Meteorol. Soc., 10, 2341-2356.

Augustine, J.A., C.R. Cornwall, G.B. Hodges, C.N. Long, C.I. MEDinA and J.J. DeLuisi (2003): An automated method for MFRSR calibration for aerosol optical depth analysis with application to an Asian dust outheak over the United States, J. Appl. Meteorol., 42 (2), 266-278.

BERGER, D.S. (1976): The sunburning ultraviolet meter: design and performance, Photochem. Photobiol., 24, 587-593.

Bigelow, D.S., J.R. Slusser, A.F. Beaubien and J. H. GIBSON (1998): The USDA ultraviolet radiation monitoring program, Bull. Amer. Meteorol Soc., 79, 601-615.

BlumthaleR, M. and W. AMBACH (1986): Messungen der temperatur koeffizienten des Robertson-Berger sunburn meters und des Eppley UV-radiometer, Arch. Meteorol. Geophys. Bioklimatol. Ser. B, 36, 357-373.

BojKov, R., L. Bishop, W.J. HiLl, G.C. REINSEL and G.C. TIAO (1990): A statistical trend analysis of revised Dobson total ozone data over the Northern Hemisphere, J. Geophys. Res., 95, 9785-9807.

DELUISI, J.J. and J.M. HARRIS (1983): A determination of the absolute radiant energy of a Robertson-Berger meter sunburn unit, Atmos. Environ., 17, 751-758.

DeLuisi, J.J., J. Wendell and F. KREINER (1992): An examination of the spectral response characteristics of seven Robertson-Berger meters after long-term use, Photochem. Photobiol., 56, 115-122.

DifFEY, B.L. (1991): Solar ultraviolet radiation effects on biological systems, Phys. Med. Biol., 36, 299-328.

Di SARra, A., T. Di Iorio, M. Cacciani, G. FiocCo and D. FUÀ (2001): Saharan dust profiles measured by lidar at Lampedusa, J. Geophys. Res., 106 (10), 10,33510,348 .

EARly, E., A. Thompson, C. Johnson, J.J. DeLuisi, P. Disterhoft, D. Wardle, E. Wu, W. Mou, Y. Sun, T. LUCAS, T. MESTECHKINA, L. HARRISON, J. BERNDT and D.S. HAYES (1998): The 1995 North American interagency intercomparison of ultraviolet monitoring spectroradiometers, J. Res. Nat. Inst. Stand. Technol., 103 (1), 15-61.

ECK, T.F., P.K. Bhartia and J. KERR (1995): Satellite estimation of spectral UV-B irradiance using TOMS derived total ozone and UV reflectivity, Geophys. Res. Lett., 22, 611-614.

FlOWERS, E.C., R.A. MCCORMICK and K.R. KURFIS (1969): Atmospheric turbidity over the United States, 19611966, J. Appl. Meteorol., 8, 955-962.
Herman, J., P.K. Bhartia, J. Ziemke, Z. Ahmad and D. LARKO (1996): UV-B radiation increases from decreases in total ozone, Geophys. Res. Lett., 23, 2117-2120.

Hicks, B.B., J.J. DeLuisi and D.R. MATt (1996): The NOAA Integrated Surface Irradiance Study (ISIS) - A new surface radiation monitoring network, Bull. Amer. Meteorol. Soc., 77, 2857-2864.

Kalliskota, S., J. Kaurola, P. TaAlas, J.R. Herman, E.A. CELARIER and N.A. KROTKOV (2000): Comparison of daily UV doses estimated from Nimbus 7/TOMS measurements and ground-based spectroradiometric data, J. Geophys, Res., 105, 5059-5067.

KAYE, J.A., B.B. HiCKS, E.C. WEATHERHEAD, C.S. LONG and J. SLUSSER (1999): U.S. UV interagency monitoring program established and operating, EOS, Trans. Amer. Geophys. Union, 80, 113-116.

KrotKov, N.A., P.K. Bhartia, J. HeRman, V. FiOletov and J. KERR (1998): Satellite estimation of spectral surface UV irradiance in the presence of tropospheric aerosols, 1, Cloud-free case, J. Geophys. Res., 103, 8779-8794.

LAntz, K.O., P. Disterhoft, J.J. DeLuisi, E. EARly, A. Thompson, D. Bigelow and J. Slusser (1999): Methodology for deriving clear-sky erythema calibration factors for UV broadband radiometers of the U.S. Central UV Calibration Facility, J. Geophys. Res., 16, 1736-1752.

LONG, C.N. and T.P. ACKERMAN (2000): Identification of clear skies from broadband pyranometer measurements and calculation of downwelling shortwave cloud effects, J. Geophys. Res., 105 (D12), 15,609-15,626.

Long, C.S., A.J. Miller, H.-T. LeE, J.D. Wild, R.C. PRZYWARTY and D. HUFFORD (1996): Ultraviolet index forecasts issued by the National Weather Service, Bull. Amer. Meteorol. Soc., 77, 729-748.

McKenzie, R.L., K.J. Paulin, G.E. BodeKer and A.P. STURMAN (1998): Cloud cover measured by satellite and from the ground: relationship to UV radiation at the surface, Int. J. Remote Sens., 19, 2969-2985.

RoBERTSON, D.F. (1972): Solar ultraviolet radiation in relation to human sunburn and skin cancer, Ph.D. Dissertation, Dept. Physics, University of Queensland, pp. 131.

Schafer, J.S., V.K. SAXENA, B.N. Wenny, W. BARnARD and J.J. DELUISI (1996): Observed influence of clouds on ultraviolet-B radiation, Geophys. Res. Lett., 23, 2625-2628.

Scotto, J., G. CotTon, F. URBACh, D. BERGER and T. FEARS (1988): Biologically effective ultraviolet radiation: surface measurements in the United States, 1974 to 1985, Science, 239,762-764.

Weatherhead, E.C., G.C. Tiao, C. Reinsel, J.E. FREDERICK, J.J. DELUISI, D. CHOI and W. TAM (1997): Analysis of long-term behavior of ultraviolet radiation measured by Robertson-Berger meters at 14 sites in the United States, J. Geophys. Res., 102, 8737-8754.

WENNY, B.N., J.S. SCHAFER, J.J. DELUISI, V.K. SAXENA, W.F. BARNARD, I.V. PETROPAVLOVSKIKH and A.J. VERGAMINI (1998): A study of regional aerosol radiative properties and effects on unltraviolet-B radiation, J. Geophys. Res., 103, 17,083-17,097. 